\title{
EXPERIMENTAL THIAMIN DEFICIENCY AS A CAUSE OF DEGENERATION IN THE VISUAL PATHWAY OF THE RAT*
}

\author{
BY \\ F. C. RODGER \\ Department of Physiology, Medical School, University of Durham
}

THAT the fundamental alteration in the visual pathway in thiamin deficiency might be biochemical and not cellular is an opinion that has been freely expressed; yet, as there is little doubt that such a deficiency leads to a widespread degeneration of the central vestibular neurones (Swank and Prados, 1942), it seems reasonable enough to expect that the visual neurones might be similarly affected.

It is surprising, in view of the possible relationship between thiamin and nutritional amblyopia, to discover how little experimental work on the subject has been performed. Most of the pioneers in this field were, of course, under the impression that thiamin filled the role earlier assigned to the hypothetical anti-beriberi vitamin. They believed wrongly that they were inducing only a thiamin deficiency by feeding birds with polished rice. Optic nerve degeneration in experiments of this nature is described by Barletta (1932) and Marchesini and Papagno (1935).

Involvement of the visual pathway in animals on a diet deficient only in the heat labile member of the B complex was noticed by Prickett (1934) in rats, and by Peters (1934) in pigeons.

The blindness which they describe, however, was a subjective finding in the terminal stages of an acute experiment. There might, then, be an explanation for it other than a cellular degeneration of the visual neurones. When animals are severely deficient, they become no longer interested in their surroundings, and need a deal of arousing, fatigue and lethargy being dominant signs. For this reason, subjective investigation of an animal's response to visual stimuli in the terminal stages would appear to be of slight value. The rest of Peters' work, however, is of such a high order that perhaps more stress has been laid upon this observation than was intended.

The series of painstaking experiments on thiamin deficiency undertaken by Swank and his various collaborators constitute the main argument in favour of thiamin being an antineuritic vitamin. In addition, Swank and Prados (1942), describe degeneration of the optic fibres within the central nervous system in an avian thiamin deficiency, induced by administering autoclaved yeast and a low protein diet. This seems an excellent paper, and most of the criticism it has aroused appears not to be justified.

* Received for publication July 14, 1952. 
Although primarily interested in the vestibular system, Swank and Prados noted that the central terminations of the optic fibres in the deficient birds were either grossly thickened or fragmented; in the severe cases this was associated with sclerosis of the related cells within the optic lobes. We cannot of course consider the optic lobe of the pigeon as being the homologue of the lateral geniculate body in man. Primitive geniculate bodies are already present in teleosts, for example, which possess optic lobes in addition.

One criticism levelled against Swank by Shaw and Phillips (1945) was that food placed in the pigeon's crop is not always ultimately swallowed and digested. More serious is the criticism that the diet lacked many amino acids not required by mammals but essential to birds. Could absence of these be the causative factor in producing degeneration? Prados and Swank (1942) had the last word: they produced the same type of degeneration in mammals (kittens), but unfortunately their claims and conclusions are there less clearly expressed.

Such, then, is the meagre positive evidence that exists.

A somewhat larger number of workers interested in this problem, who describe experiments in which they could find no significant degenerative changes within the visual pathway in thiamin deficiency, includes Engel and Phillips (1938), McDermott and others (1943), and Leinfelder and Robbie (1947). One must mention, too, the positive opinions of Zimmerman (1943) whose brilliant work on canine nutritional neuropathies is well known to workers in this field; there is no specific experiment of his own devoted to a study of the visual path, but he stated that he had never been convinced that optic atrophy occurred experimentally in dogs, pigeons, or rats as a result of thiamin deficiency.

This brief account of the relevant literature shows that the evidence is scanty and extremely conflicting; but the various discrepancies and disagreements proved helpful in planning the present experiments.

\section{Methods}

In all our experiments, rats between $50-100 \mathrm{~g}$. in weight were preferred. The individual weights are given in detail below.

The animals were weighed on the first day of the institution of the experimental diet, at weekly intervals, and on the last day. On each occasion, the weighing took place before feeding. At the same time, the opportunity was taken to examine the eyes, skin, fur, gait, and posture. This was done in daylight on a raised examination table. Towards the termination of each experiment a general examination was undertaken daily.

The animals were housed in individual cages fitted with wide wire mesh floors. The cages were shaded, draught-free, and kept in a room of constant temperature $\left(65-75^{\circ} \mathrm{F}\right.$.).

The principle of paired feeding was adopted, the control animal in nearly all cases being from the same litter.

Force-feeding was not used. In the chronic deficiencies, we learned by trial experiments how to prevent anorexia. In those few cases in which loss of appetite 
persisted, we feel paired feeding adequately covered the probable effects of inanition. In our experience, anorexia is not such a striking symptom in chronic thiamin deficiency as it appears to be in a deficiency of the entire B complex (Drummond and Marrian, 1926). The appetite could be brought back by the administration of as little as $10 \mu \mathrm{g}$. of thiamin hydrochloride. It rarely reached a severe degree (i.e., less than $2 / 3$ eaten) until the weight had fallen to its original level. Even then, by careful nursing, the animals could be made to eat as much as $7.5-10.0 \mathrm{~g}$./day per $100 \mathrm{~g}$. body weight, which is far from starvation level in a rat exhibiting a marked disinclination to exercise.

In the acutely deficient rats, so rapid was the onset of severe symptoms that force-feeding - a matter of great difficulty in rats-led to sudden death, and was therefore abandoned. In such cases, having previously carefully investigated the morphological lesions resulting from inanition, it was a simple matter to take them into account in the final assessment.

The criterion taken as being most characteristic (in rats) of a chronic thiamin deficiency was a reduction in heart rate. When this fell to the neighbourhood of 300 beats/min. it was felt that the animals were deficient whether gross clinical manifestations were evident or not.

The bradycardia of experimental thiamin deficiency is generally accepted as being pathognomonic. It cannot be caused by inanition unless this is very prolonged, which was never the case in our experiments. It was, moreover, never found in any of the control animals. Without altering the diet, the bradycardia can be eliminated by administering $1 \mathrm{mg}$. intraperitoneal thiamin hydrochloride. If the rate fell below 200 beats/min., we were less successful in obtaining recovery.

The cause of this bradycardia is not known. Drury, Harris, and Maudsley (1930), though they produced in some rats a slight increase in heart rate by vagal section, failed to restore it to the normal values. One must presume, therefore, that it is of sinus origin. Our method of recording the heart rates was essentially that described by Harris and his colleagues, and the procedure they described was followed as carefully as possible. It appears that when the recordings are made under standard conditions, conclusive evidence may be obtained by comparing the figures with those for the control rats, whose heart rates are recorded at the same time.

In acute thiamin deficiency, however, bradycardia could not be taken as an index of the success of the experimental diet, for this appears in our experience to develop only in the terminal stages, when the animals are moribund. The nervous disorders characteristic of chronic deficiency become manifest sometimes before, usually after, the appearance of bradycardia. In acute deficiency, they always coincided, and so, in the latter, it was the nervous symptoms which determined the termination of the experiment. In short, the acutely deficient rats were killed when they were seen to be dying, and the chronically deficient when bradycardia was in the neighbourhood of 300 beats $/ \mathrm{min}$.

On termination of the experiments, the rats were killed by decapitation under urethane. The brains, optic nerves, and eyeballs were then removed and fixed within 10 minutes in 10 per cent. neutral formalin. Such speedy fixation is essential if autolytic distortions are to be prevented. Some twigs of sciatic nerve taken at random from each group were similarly treated. As the primary interest was in the visual path, it was not possible to investigate each sciatic nerve in every case in its entirety. 
The pathological alterations in the peripheral nerves in thiamin deficient animals do not appear to be as clear-cut as the clinical manifestations described above. (It is this finding which suggests that beriberi is not due solely to an absence of thiamin). According to numerous authors (Prickett, 1934; Davison and Stone, 1937; Engel and Phillips, 1938; Prickett, Salmon, and Schrader, 1939) examination of the peripheral nerves of rats fed on diets containing autoclaved yeast has revealed no significant morphological differences from those of control animals. The slight changes which occurred are ascribed to inanition. Berry, Neumann, and Hinsey (1945) placed cats on a thiamin-free diet for as long as 116 days but found no trace of degeneration in the peripheral nerves, and the same conclusion with regard to swine was reached by Follis and others (1943) and by Wintrobe and others (1944).

This fact is not, we feel, generally appreciated, but the evidence is too strong to ignore. To have used peripheral nerve preparations as a means of controlling the experiment, therefore, would appear somewhat pointless.

\section{Constitution of Diets}

(1) Daily Caloric Requirements. - A rat of $75 \mathrm{~g}$. will thrive on approximately $10 \mathrm{~g}$. food daily; a rat of $150 \mathrm{~g}$. requires $15 \mathrm{~g}$., and rats above $200 \mathrm{~g}$. vary in their demands. All rats in the experiment were less than $150 \mathrm{~g}$. in weight, and $15 \mathrm{~g}$. food was fed to each irrespective of weight. Thus, no rat, control or otherwise, was fed at too low a level. It was considered quite normal if less than $5 \mathrm{~g}$. of the daily ration was left uneaten by rats of $75 \mathrm{~g}$. or less.

(2) Composition of Diets.-The " stock" diet was made up as follows:
(i) Casein $\quad \ldots \quad \ldots \quad \ldots \quad \ldots \quad 15$
(ii) Salt mixture $\quad \ldots \quad \ldots \quad \ldots \quad 4$
(iii) Glucose ... $\quad \ldots \quad \ldots \quad \ldots \quad 70,100$
(iv) Water soluble vitamins (W.S.V.) 10
(v) Fat soluble vitamins (F.S.V.) ... 1 ,

\section{(3) Details of Dietary Components}

(i) Casein (lactic casein, unextracted)

$\begin{array}{lrlllrl}\text { Moisture } & \ldots & \ldots & \ldots & \ldots & 10 \\ \text { Fat } & \ldots & \ldots & \ldots & \ldots & 2.1 & \\ \text { Nitrogen } & \ldots & \ldots & \ldots & \ldots & 13.5 & 15 \\ \text { Calcium } & \ldots & \ldots & \ldots & \ldots & 0.04 & \end{array}$

It should be noted that the composition of the diet is based on dry weights, an allowance being made for the $10 \%$ of water present in casein.

The quantity of protein is low, of course, as the proportion of carbohydrate is required to be high. This precipitates thiamin deficiency (Yudkin, 1951). The protein is quite sufficient, however, for growth. It is vitamin-free.

(ii) Salt Mixture (g.)*

$\begin{array}{lllc}\text { Sodium chloride } & \ldots & \ldots & 22 \\ \text { Calcium phosphate } & \ldots & 130 \\ \text { Potassium citrate } & \ldots & \ldots & 125 \\ \text { Magnesium sulphate } & \ldots & 30 \\ \text { Iron citrate } & \ldots & \ldots & 5 \\ \text { Trace mixture } & \ldots & \ldots & \mathbf{0 . 7} \\ & & & 312.7\end{array}$

\section{Trace Mixture}

Potassium iodide ... $\quad \ldots \quad 12$

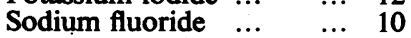

Manganese sulphate $\quad \ldots \quad 2$

$\begin{array}{llll}\text { Cuprous iodide } & \ldots & \ldots & 1\end{array}$

$\begin{array}{llll}\text { Potash alum } & \ldots & \ldots & 1 \\ & & \ldots & \end{array}$

Zinc sulphate $\quad \ldots \quad \ldots \quad 1$

* This corresponds to DL6, a salt complex prepared by Glaxo Laboratories, Greenford, Middlesex, and was purchased from them. In the initial planning of the diets, the helpful advice of Dr. W. F. J. Cuthbertson of that same laboratory is gratefully acknowledged. 
The manganese and magnesium proportions are higher than most workers prescribe to ensure good growth, and the normal excitability of the nervous system. There is nothing unusual in the quantities of the other salts present.

(iii) Glucose.-That incorporated in the diet was of the pure medicinal variety.

(iv) Water Soluble Vitamins

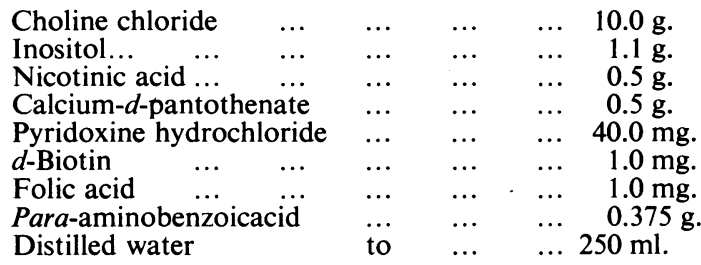

Riboflavine, $150 \mathrm{mg}$., was then dissolved in the least amount of boiling 5 per cent. acetic acid, shaken in $50 \mathrm{ml}$. non-methylated 95 per cent. alcohol and added. Finally, distilled water brought the total volume up to $500 \mathrm{ml}$.

The daily dose of W.S.V. was $1 \mathrm{ml}$. per rat.

The absence of ascorbic acid from this complex is not an oversight. Rats need not be given vitamin $\mathrm{C}$, as they synthesize it readily in the intestine. On a diet deficient in this factor considerable quantities are found in the livers, even after a long period (Coward, 1947).

If the relationship of riboflavine to thiamin is to be investigated, the former vitamin can be made up separately, the composition of W.S.V. being adjusted accordingly. Riboflavine itself is administered at the same level $(150 \mathrm{mg}$. in $500 \mathrm{ml}$.). The daily dose per rat is $1 \mathrm{ml}$. as in the original W.S.V.

The full maintenance dose of thiamin required by rats above $50 \mathrm{~g}$. in weight is in the region of $10 \mu \mathrm{g}$. a day. Woolley and White (1943) claim that mice require $2 \mu \mathrm{g}$.; Arnold and Elvehjem (1938), that chicks require $10 \mu \mathrm{g}$; and Swank and Bessey (1941) that pigeons require $20 \mu \mathrm{g}$.

Nevertheless, we administered thiamin at the extremely high level of $500 \mu \mathrm{g}$. daily to the control animals, giving $5 \mu \mathrm{g}$. only to the deficient, as follows:

(a) Full maintenance dose (thiamin full)

(b) Minimal maintenance dose (thiamin minimal) Thiamin hydrochloride $250 \mathrm{mg}$. Distilled water to $500 \mathrm{ml}$.

Daily dose per rat $1 \mathrm{ml}$. $(0.5 \mathrm{mg}$.) $\begin{array}{lllr}\text { Thiamin hydrochloride } & \ldots & 5 \mathrm{mg} \text {. } \\ \text { Distilled water to } & \ldots & 500 \mathrm{ml} \text {. }\end{array}$

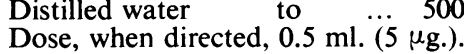

The detailed administration is given later with each experiment.

(v) Fat Soluble Vitamins

$\begin{array}{llllr}\beta \text {-carotene }\left(1.2 \times 10^{6} \text { i.u. }\right) & \ldots & \ldots & 5 \mathrm{mg} . \\ \text { Calciferol }\left(0.2 \times 10^{6} \text { i.u. }\right) & \ldots & \ldots & 5 \mathrm{mg} . \\ \alpha \text {-tocopherol acetate } \quad \ldots & \ldots & \ldots & 2 \mathrm{mg} . \\ \text { Arachis oil to to } & \ldots & \ldots & \ldots & 100 \mathrm{~g} . \\ \text { Daily dose per rat } 0.1 \mathrm{ml} \text {. (about } & \text { drops). }\end{array}$

Vitamin K (2 methyl-1, 4-naphtha-quinone) was not included, for no changes have been detected in the tissues of animals deficient in vitamin $\mathrm{K}$, apart from the physiological defects associated with haemorrhage.

Ferraro and Roizin (1943), in an interesting paper on vitamin K deficiency in rats, describe the presence of multiple haemorrhages in the brain. Best and Taylor (1950), however, maintain that it is not possible to induce a haemorrhagic tendency in rats owing to the high degree of synthesis going on in the intestine.

As the absence of vitamin $K$ does not affect the central nervous system, it was omitted, a practice in keeping with that of other workers. 


\section{Histological Techniques}

The eight different histological techniques employed are shown in Table I. A full description with their inherent fallacies has been given elsewhere (Rodger, 1951). It should be stressed that before the experiments here described were performed, a year was spent in becoming familiar with the anatomy of the rat visual path, the histological methods of choice, and the appearance of the visual neurones in various known diseases.

TABLE I

HISTOLOGICAL TECHNIQUES

\begin{tabular}{|c|c|c|c|c|c|c|c|c|}
\hline Part of Visual Path & $\begin{array}{l}(1) \\
\text { Nissl }\end{array}$ & $\stackrel{(2)}{\text { Giemsa }}$ & $\begin{array}{l}\text { (3) } \\
\text { Triple }\end{array}$ & $\begin{array}{l}\text { (4) } \\
\text { Polarized } \\
\text { Light }\end{array}$ & $\stackrel{(5)}{\text { Marchi }}$ & $\begin{array}{l}(6) \\
\text { Weigert- } \\
\text { Pal }\end{array}$ & $\begin{array}{l}\text { (7) } \\
\text { Loyez. }\end{array}$ & $\begin{array}{l}\text { (8) } \\
\text { Silver } \\
\text { Nitrate }\end{array}$ \\
\hline $\begin{array}{lll}\text { Retina } & \ldots & \ldots\end{array}$ & $\mathbf{X}$ & $\mathbf{X}$ & $\mathbf{X}$ & & & & & \\
\hline Optic Nerve $\left\{\begin{array}{l}\text { Axons ... } \\
\text { Myelin }\end{array}\right.$ & & & & $\begin{array}{l}X \\
X\end{array}$ & $\mathrm{X}$ & $\mathrm{X}$ & $\mathrm{X}$ & $\mathrm{X}$ \\
\hline Optic Tract $\left\{\begin{array}{l}\text { Axons ... } \\
\text { Myelin }\end{array}\right.$ & & & & $\begin{array}{l}\text { occasionally } \\
\text { occasionally }\end{array}$ & $\mathrm{X}$ & $\mathbf{X}$ & $\mathbf{X}$ & $\mathbf{X}$ \\
\hline $\begin{array}{l}\text { Lateral } \\
\text { Geniculate } \\
\text { Body }\end{array}\left\{\begin{array}{l}\text { Cells } \ldots \\
\text { Processes } \\
\text { Myelin }\end{array}\right.$ & $\mathbf{X}$ & $\mathbf{X}$ & & & & & $\mathbf{X}$ & $\mathbf{X}$ \\
\hline
\end{tabular}

The rat visual pathway is easily dissected. The cerebral hemispheres are removed by hand. Then, splitting the chiasma, and laying the brain on its lateral side, one may excise the optic nerve, half-chiasma, tract, and lateral geniculate body in one piece. Portions of the thalamus and cerebral peduncle are included. The visual fibres leave the tract to synapse in the dorsal nucleus of the lateral geniculate body. By this dissection, an opportunity is afforded of studying the nerve, tract, and dorsal nucleus in the same section. The section may be described as representing the anteroposterior and dorsoventral diameters, and as it is possible to examine the entire length of the nucleus by serial sections, observations may be also made in its medio-lateral diameter.

\section{Plan of Experiments}

In several trial experiments, it was found that the onset of nervous manifestations of acute deficiency began very suddenly-within $24 \mathrm{hrs}$ or so of the appearance of anorexia and bradycardia. We wondered, therefore, if these manifestations might not have resulted from inanition. Furthermore, if anatomical damage had caused the nervous disorders, it might be that this, too, depended on caloric inadequacy.

These possibilities, unlikely though they seemed, and the further desire to discover whether the nervous symptoms were due to lack of calories or lack of vitamins, led to the framing of the first two of the six following experiments :

(1) Caloric inadequacy without exogenous vitamins.

(2) Caloric inadequacy associated with full vitamin intake. 
(3) Acute deficiency in thiamin due to administration of the analogue.

(4) The same, recovered.

(5) Reduced thiamin intake associated with a high carbohydrate diet, inducing a chronic deficiency.

(6) The same, recovered.

\section{Results}

(1) Caloric Inadequacy without Exogenous Vitamins

Diet.-

$$
\left.\begin{array}{lllll}
\text { Potato starch } & \ldots & \ldots & \ldots & 70 \\
\text { Wheat straw pulp } & \ldots & \ldots & \ldots & 20 \\
\text { Agar-sucrose } & \ldots & \ldots & \ldots & 10
\end{array}\right\} 100
$$

Clinical Behaviour.-On this diet, fed ad libitum, six rats (average weight $200 \mathrm{~g}$.) died at the end of 11 days. They were perfectly healthy until the morning of the 10th day when they were seen to be very inactive, and to have assumed a crouching position. They could be roused only with difficulty, their movements were inco-ordinated, and their postural sense appeared diminished. Next morning they had violent convulsions while on the examination table and within half an hour were dead.

Pathological Observations.-Vacuolation of the ganglion cells of the retina and geniculate body was the only cytological change found. As vacuolation of the retinal cells is a very common artefact, more common than swelling, we are inclined to consider that this is the explanation of the finding.

The myelin sheaths viewed by polarized light were hazy in outline and their substance somewhat granular (Fig. 1), and this was also true of the sciatic twigs, but Loyez and Marchi stain

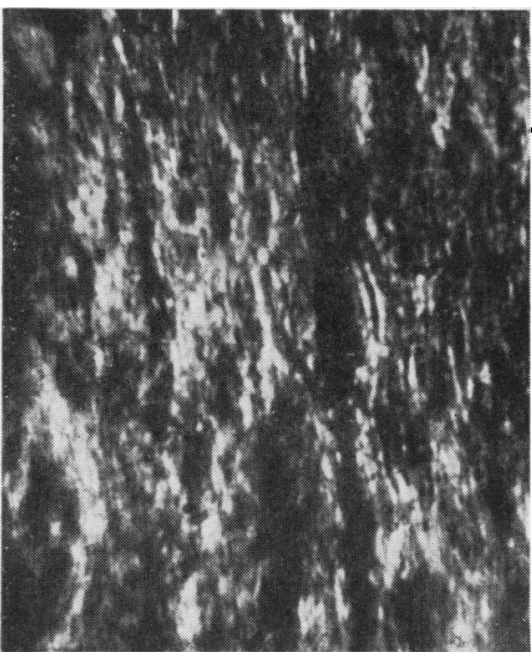

FIG. 1.-Granular isotropism of optic-tract myelin sheaths in caloric inadequacy without exogenous vitamins. Polarized light $\times 250$.

revealed no abnormality. No sign of any degeneration involving the nerve fibres was found.

(2) Caloric Inadequacy associated with Full Vitamin Intake

Diet.-

$$
\begin{array}{lcccc|c}
\text { Potato starch } & \ldots & \ldots & \ldots & 70 \\
\text { Wheat straw pulp } \ldots & \ldots & \ldots & 20 & 100 \\
\text { Agar-sucrose } & \ldots & \ldots & \ldots & 10 \\
\text { W.S.V. (less thiamin) } & \ldots & \ldots & 6 \mathrm{ml} .
\end{array}
$$

Clinical Behaviour.-Six rats of average weight $160 \mathrm{~g}$. and members of the same litter were fed the usual $15 \mathrm{~g}$. daily for $24 \mathrm{hrs}$. They were then divided into two groups: 
(A) remained on the same diet

(B) received $2.0 \mathrm{mg}$. thiamin (i.p.) daily in addition.

On the 18th day, the three rats in Group A and one of the rats in Group B died. Two days later the remaining two rats in Group B, now moribund, were killed. The manner of death in those permitted to die was exactly as described in Experiment 1.

Pathological Observations.-There were no essential differences between the two groups, A and B.

In the retina, the outline of many of the cells was indistinct, the cytoplasm staining homogeneously, and the nucleus containing dark-stained granules.

The geniculate cells exhibited signs of severe somatic disorder. The Nissl bodies in many cells were clotted and darkly stained. The cell outlines were frequently badly distorted. Some of the astrocytes were swollen, and there were many hypertrophied cerebral histiocytes (rod cells) with darkstaining nuclei. Long oligodendrocytic chains lay in the fibre pathways.

The nerve fibres themselves were tortuous, but not otherwise distorted. The endings were unaffected.

- The myelin sheaths revealed more positive changes than in the previous series, but, in view of the advanced"cellular damage present, these changes were much less than we expected. There was a similar slight degree of demyelinization in the sciatic nerves, revealing itself in polarized light in both instances as a granular isotropism.

(3) Acute Deficiency in Thiamin due to Administration of the Analogue

Diet.-

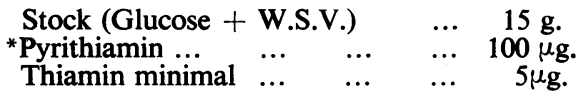

Clinical Behaviour.-The weights and heart rates are shown in Table II.

TABLE II

EXPERIMENT 3 (DURATION 17 DAYS)

\begin{tabular}{c|c|c|c|c|c|c|l}
\hline \multirow{2}{*}{ Rat No. } & \multicolumn{4}{|c|}{ Weights (g.) } & \multicolumn{2}{|c|}{ Heart Rates (beats/min.) } & \multirow{2}{*}{ Disposal } \\
\cline { 2 - 6 } \cline { 5 - 6 } & Initial & Final & Difference & Initial & Final & Difference & \\
\hline 1 & 90 & 80 & -10 & 500 & 250 & -250 & Killed \\
2 & 80 & 87 & +7 & 500 & 240 & -260 & Killed \\
3 & 75 & 95 & +20 & 510 & 310 & -200 & Killed \\
4 & 75 & 75 & 0 & 500 & - & - & Killed \\
5 & 75 & 75 & 0 & 500 & - & - & Killed \\
6 & 85 & 90 & +5 & 500 & 300 & -200 & Killed \\
7 & 80 & 77 & -3 & 500 & - & - & Killed \\
8 & 117 & 100 & -17 & 400 & 200 & -240 & Died during recording \\
9 & 100 & 102 & +2 & 480 & 300 & -180 & Killed \\
10 & 85 & 88 & +3 & 500 & - & - & Killed \\
11 & 92 & 96 & +4 & 490 & - & - & Killed \\
12 & 90 & 89 & -1 & 460 & - & - & Killed \\
\hline
\end{tabular}

* As this was not available in Great Britain at the time, this was generously supplied by the Research Department, Merck and Company, Rahway, New Jersey. It was prepared in their laboratories, and renamed Neopyrithiamine, and we found it most effective. 
On the 17th day all the animals were found to exhibit the same clinical picture. When they were picked up by the tail a convulsion appeared, and, on recovery, spasticity of the hind legs was marked, and occasionally the animal fell over sideways in spasm. Both sides seemed equally affected. Some of the animals were ultimately (minutes) unable to move, assuming what later proved to be a characteristic pose, lying flat on their abdomens with their limbs extended outwards. Spontaneous convulsions appeared in two of them. Anorexia was first seen about 36 hrs before death.

Pathological Observations.-There was cloudy swelling of the retinal bipolar and ganglion cells (Fig. 2). This is of doubtful significance.

The optic nerve fibres were slightly more tortuous than normal.

There were no other signs of degeneration in retinae, nerve fibres, myelin sheaths, or geniculate bodies.

A few of the twigs of the sciatic nerve revealed marked degeneration of myelin (Fig. 3), except in Rats 3 and 5, where no abnormality was discovered in the twigs removed for examination.

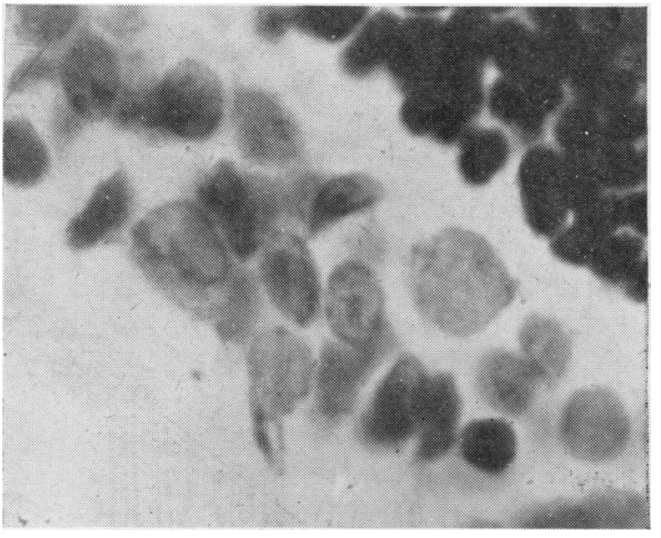

FIG. 2.-Cloudy swelling of the retinal bipolar cells in acute thiamin deficiency. Triple $\times 1600$.

\section{(4) As in Experiment 3, Recovered}

Diet.-As in Experiment 3.

Clinical Behaviour.-Weights and heart rates are shown in Table III.

TABLE III

EXPERIMENT 4 (DURATION 60 DAYS)

\begin{tabular}{|c|c|c|c|c|c|c|c|}
\hline \multirow{2}{*}{ Rat No. } & \multicolumn{3}{|c|}{ Weights (g.) } & \multicolumn{3}{|c|}{ Heart Rates (beats/min.) } & \multirow{2}{*}{ Disposal } \\
\hline & Initial & At 15 days & Final & Initial & At 15 days & Final & \\
\hline $\begin{array}{l}1 \\
2 \\
3 \\
4 \\
5 \\
6\end{array}$ & $\begin{array}{l}130 \\
110 \\
165 \\
110 \\
120 \\
135\end{array}$ & $\begin{array}{l}120 \\
111 \\
185 \\
107 \\
115 \\
121\end{array}$ & $\begin{array}{l}165 \\
148 \\
235 \\
\overline{155} \\
-\end{array}$ & $\begin{array}{l}440 \\
480 \\
440 \\
500 \\
480 \\
460\end{array}$ & $\begin{array}{l}250 \\
300 \\
360 \\
200 \\
240 \\
-\end{array}$ & $\begin{array}{l}440 \\
460 \\
420 \\
- \\
480 \\
-\end{array}$ & $\begin{array}{l}\text { Killed } \\
\text { Killed } \\
\text { Killed } \\
\text { Died 13th day } \\
\text { Killed } \\
\text { Died }\end{array}$ \\
\hline
\end{tabular}

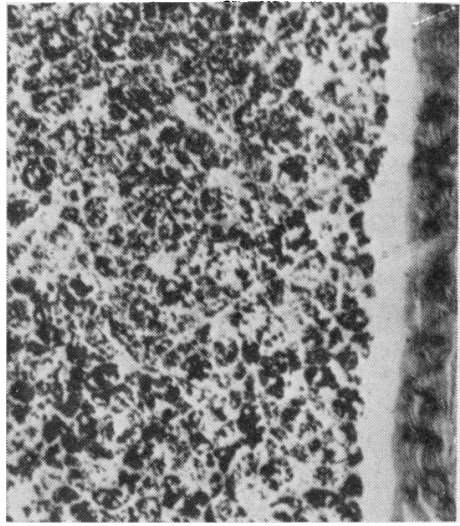

FIG. 3. - Gross destruction of myelin in main branch of sciatic nerve in acute thiamin deficiency. A portion of an unaffected twig can be seen on the right. Marchi $\times 140$. 
Rat 4 died on the 13th day. Rat 6 died suddenly during the recordings. The others were all spastic and inco-ordinated on the 15th day when their diet was restored. Rats 1 and 5 were given intraperitoneal thiamin as their heart rates were so low, and this was repeated for 3 days; otherwise they might not have lived. The four survivors (Rats 1, 2, 3, and 5) were killed on the 60th day.

Pathological Observations.-No signs of degeneration or repair in the visual pathway nor sciatic nerves were seen in the recovered rats.

\section{(5) Reduced Thiamin Intake associated with High Carbohydrate Diet,} Diet.inducing Chronic Deficiency

$$
\begin{aligned}
& \text { Stock (Glucose }+ \text { W.S.V.) } \\
& \text { Thiamin minimal } \ldots
\end{aligned}
$$

The adoption of a preconceived plan for the administration of thiamin to the group was rejected. We decided each animal required individual attention. A daily dose of $2 \mu \mathrm{g}$. was, therefore, administered individually until the first signs of anorexia. The dose was then increased in that rat to $5 \mu \mathrm{g}$. until the appetite returned, when $2 \mu \mathrm{g}$. was once again given, ad infinitum.

Clinical Behaviour.-A As Table IV shows, Rats, 1, 3, and 4 existed quite happily on a daily maintenance dose of $2 \mu \mathrm{g}$., although they had gained on the average only about $18 \mathrm{~g}$. in weight after 180 days. Up to the 12 th week all the rats did well. The increase in weight was slow but steady. The animals were thin but fit, and their appetites had been maintained. Hereafter it was increasingly difficult to prevent anorexia in Rats 2, 5, and 6.

TABLE IV

EXPERIMENT 5 (DURATION 180 DAYS)

\begin{tabular}{|c|c|c|c|c|c|c|c|}
\hline \multirow{2}{*}{ Rat No. } & \multicolumn{3}{|c|}{ Weights (g.) } & \multicolumn{3}{|c|}{ Heart Rates (beats/min.) } & \multirow{2}{*}{ Disposal } \\
\hline & Initial & Final & Difference & Initial & Final & Difference & \\
\hline $\begin{array}{l}1 \\
2 \\
3 \\
4 \\
5 \\
6\end{array}$ & $\begin{array}{l}95 \\
90 \\
90 \\
92 \\
90 \\
90\end{array}$ & $\begin{array}{r}100 \\
90 \\
120 \\
110 \\
95 \\
89\end{array}$ & $\begin{array}{r}+5 \\
0 \\
+30 \\
+18 \\
+\quad 5 \\
-1\end{array}$ & $\begin{array}{l}500 \\
500 \\
500 \\
500 \\
500 \\
500\end{array}$ & $\begin{array}{l}480 \\
360 \\
480 \\
420 \\
340 \\
360\end{array}$ & $\begin{array}{l}-20 \\
-140 \\
-20 \\
-80 \\
-160 \\
-140\end{array}$ & Killed on 180th day \\
\hline
\end{tabular}

By the 160th day they had become bedraggled and shaky. There were no gross signs of inco-ordination, however, and they kept eating up to two-thirds of their daily ration. We observed a marked ptosis of the upper lids. Even when the animals were given a fright, the palpebral fissures remained reduced in size, and this appeared to be a true paralysis. The animals, moreover, appeared to be suffering from drop-foot, although this may have been due to fatigue. They still ate, however, and could sit up and wash 
themselves. We observed one of them regurgitate while feeding on two occasions but vomitus was never seen. When the heart rates fell below 400 beats/min. (restrained), it was decided to end the experiment.

The continued good health of the other three rats was considered to be due to intestinal resynthesis.

Pathological Observations.-Rats, 1, 3, and 4 revealed no abnormality; Rats 2, 5, and 6 each exhibited

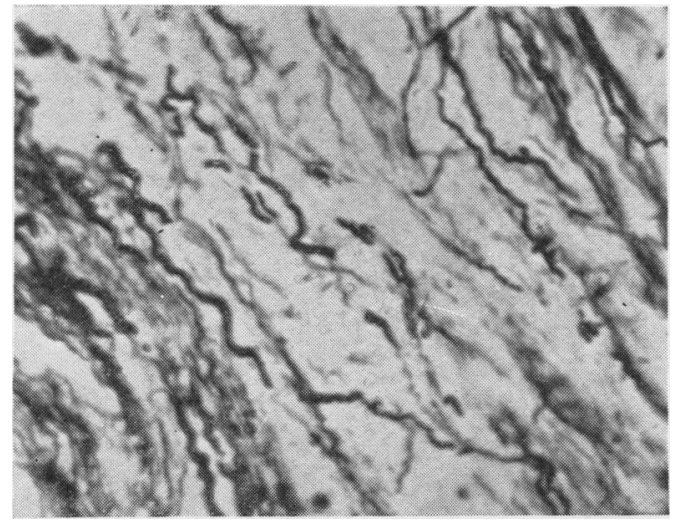

FIG. 4.-Fragmentation and tortuosity of optic-nerve terminals within dorsal nucleus in chronic thiamin deficiency. The larger fibres in the section are not fragmented. Author's silver $\times 670$.

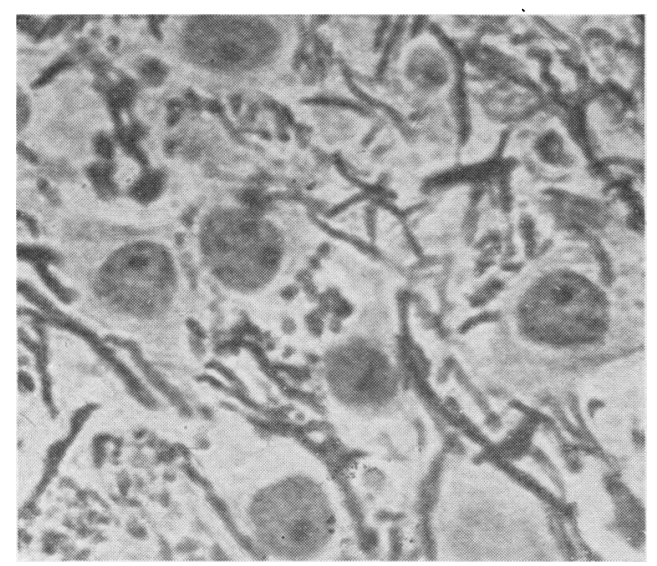

FIG. 5.-Enlargement of terminal nerve endings in chronic thiamin deficiency. Some argyrophil ring shapes are also present. Author's silver $\times 1000$. identical changes.

The retinal ganglion cells were hyperchromatic. That was the only change.

The optic nerve and tract revealed widespread signs of degeneration increasing in intensity as the fibres ascended: the nerve fibres were thickened, distorted, and very tortuous (corkscrew fibres). The terminal branches within the lateral geniculate body were similarly affected; and in addition the larger ones had fragmented (Fig. 4). There were many small black patches, which might have

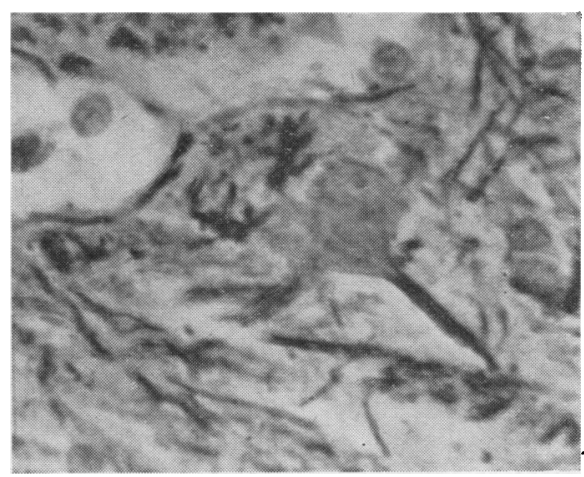

FIG. 6.-Final visual neurone within dorsal nucleus in chronic thiamin deficiency. Axon greatly swollen. Author's silver $\times 1000$.

been distorted ring shapes. We found a few endings enlarged (Fig. 5). The fibres of the third neurone as far as we could see were varicose and thickened (Fig. 6). 


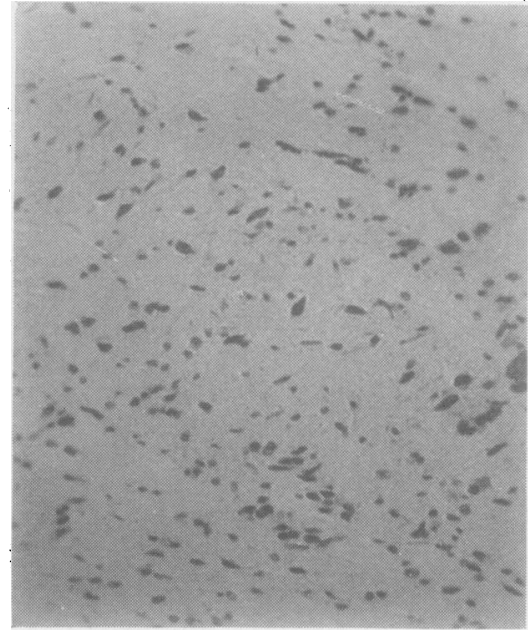

Fig. 7.-Sclerosis and hyperchromatism of visual neurones in chronic thiamin deficiency. Cf. Fig. 8. Giemsa $\times 175$.

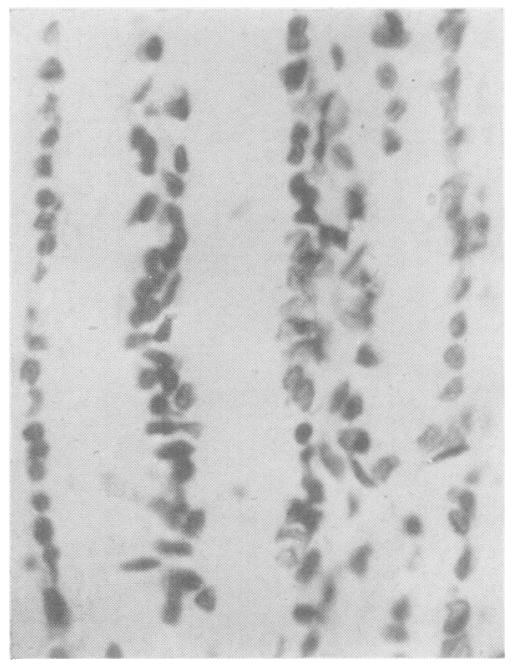

Fig. 9.-Aggregation of oligodendrocytes in chronic thiamin deficiency. Giemsa $\times 300$.

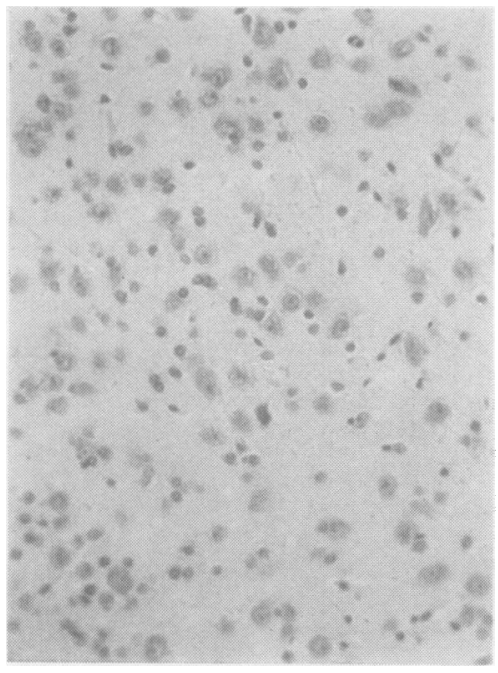

Fig. 8.-Unaffected visual neurones of dorsal nucleus in paired control animal. Giemsa $\times 175$.

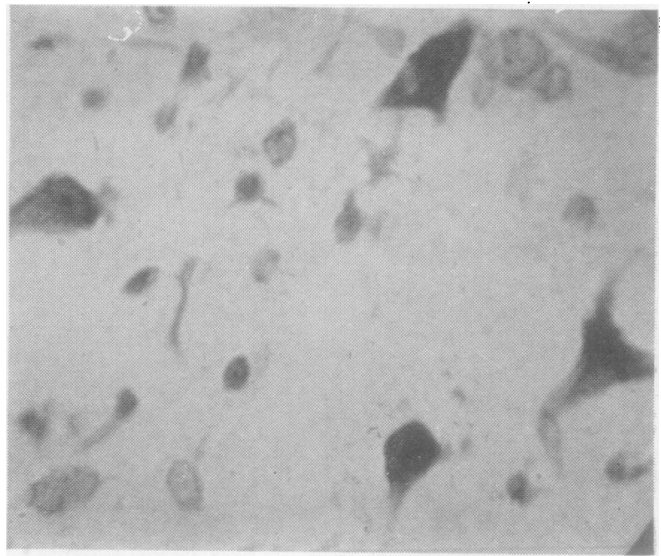

FIG. 10.-Sclerosis and hyperchromatism of visual neurones in chronic thiamin deficiency. Note presence of rod cells and cloudy swelling of astrocytes. Giemsa $\times 750$.

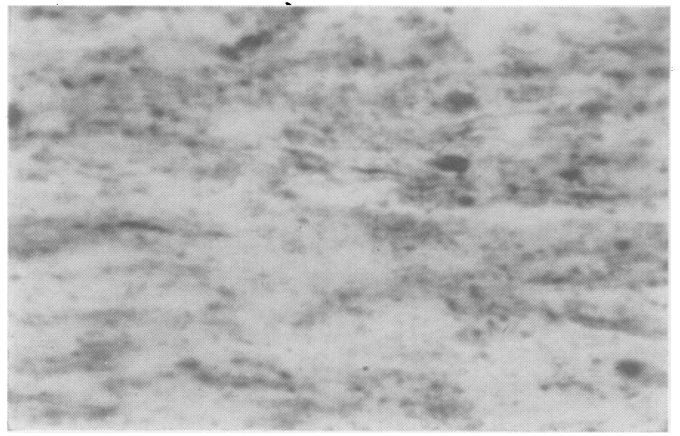

FIG. 11.-Fragmentation, globulation, and ballooning of persistent myelin sheaths in chronic thiamin deficiency. Weigert-Pal $\times 350$. 
Within the dorsal nucleus, the visual cells were nearly all hyperchromatic and sclerosed. The degree of sclerosis was not gross, but it was definite. Both nuclear and cellular outlines were distorted (Figs 7 and 8).

Within the optic nerve and tract, the oligodendrocytes had proliferated considerably into long chains (Fig. 9). These cells were of normal size, but the small amount of cytoplasm present was hyperchromatic. We did not find any evidence of satellitosis, but many rod cells were seen within the dorsal nucleus (Fig. 10).

These changes were widespread.

The myelin changes, although variable, were diffuse. In places the myelin had completely disappeared, many gitter cells being present. Where the myelin sheaths persisted, irregularity and ballooning was common (Fig. 11), and this was also true of some of the twigs of the sciatic nerves.

\section{(5A) Paired Control}

Diet.-As in Experiment 5.

Clinical Behaviour.-Table $\mathrm{V}$ shows the weights and heart rates of the six paired rats in Experiment 5A.

TABLE V

EXPERIMENT 5A, PAIRED CONTROLS (DURATION 180 DAYS)

\begin{tabular}{c|c|c|c|c|c|c|c}
\hline & \multicolumn{3}{|c|}{ Weights (g.) } & \multicolumn{2}{c|}{ Heart Rates (beats/min.) } & \multirow{2}{*}{ Disposal } \\
\cline { 2 - 6 } Rat No. & Initial & Final & Difference & Initial & Final & Difference & \\
\hline 1A & 100 & 265 & +165 & 500 & 480 & -20 & \\
2A & 90 & 180 & +90 & 500 & 480 & -20 & \\
3A & 102 & 275 & +173 & 500 & 500 & Nil & Killed on 180th day \\
4A & 95 & 290 & +195 & 500 & 460 & -40 & \\
5A & 87 & 190 & +103 & 500 & 460 & -40 & \\
6A & 90 & 200 & +110 & 500 & 480 & -20 & \\
\hline
\end{tabular}

These rats did well. Rats $2 \mathrm{~A}, 5 \mathrm{~A}$, and $6 \mathrm{~A}$, being subjected to the vagaries of appetite in the paired experimental animals, were often hungry. Latterly all were hungry, $15 \mathrm{~g}$. being evidently insufficient.

Pathological Observations. - No abnormality found.

\section{(6) As in Experiment 5, Recovered}

Diet.-As in Experiment 5.

Clinical Behaviour.-The weights and heart rates are shown in Table VI (overleaf). By the 63rd day, signs of deficiency were present. Rats 1, 3, 6, and 8 were moribund, intraperitoneal thiamin had no effect, and they died in convulsions. The others were shaky, but otherwise well, especially Rat 9, and heart rates were taken under light urethane.* Rat 5 did not 
TABLE VI

EXPERIMENT 6 (DURATION 140 DAYS)

\begin{tabular}{|c|c|c|c|c|c|c|}
\hline \multirow{2}{*}{ Rat No. } & \multicolumn{3}{|c|}{ Weights (g.) } & \multicolumn{2}{|c|}{ Heart Rates (beats/min.) } & \multirow{2}{*}{ Disposal } \\
\hline & Initial & At 14th week & Final & Initial & At 14 th week & \\
\hline 1 & 50 & 80 & - & 550 & - & Died 63rd day \\
\hline 2 & 115 & 110 & 160 & 480 & 340 & Killed 140th day \\
\hline 3 & 50 & 60 & - & 550 & - & Died 63rd day \\
\hline 4 & 55 & 85 & 100 & 500 & 320 & Killed 90th day \\
\hline 5 & 55 & 92 & - & 500 & 360 & Died during recording \\
\hline 6 & 55 & 75 & - & 500 & - & Died 63rd day \\
\hline 7 & 70 & 60 & 235 & 500 & 380 & Killed 140th day \\
\hline 8 & 55 & 70 & - & 550 & - & Died 63rd day \\
\hline 9 & 72 & 125 & 255 & 480 & 390 & Killed 140th day \\
\hline
\end{tabular}

regain consciousness. Rat 2 was spastic next day, and all the survivors (including Rat 9, which was still very active) were given intraperitoneal thiamin, and a full diet was instituted. They made an uninterrupted recovery, gaining weight rapidly. Anorexia in this experiment had been remarkably well controlled so that the paired rats (Exp. 6A) seldom had to have their intake reduced. Rat 4 was killed on the 90th day, and the rest on the 140th. There was no residual palsy.

Pathological Observations.-Changes were found in Rats 2, 4, and 7. The visual path and eyeballs of Rat 9 were normal.

The changes in the retinae, which were not striking, consisted of the presence of what appeared to be "gemastëte cells". These cells approached in size sclerosed ganglion cells, and might have been mistaken for them. The number of them present in $7 \mu$. sections outside the macular region was, nevertheless, suggestive. The ganglion cells themselves were on the whole normal, although satellitosis around them was common. The other retinal elements were unaffected.

The visual cells in the dorsal geniculate nuclei were almost entirely normal; here and there a few were sclerosed, and there was widespread hyperchromatism of the glia, and some evidence of satellitosis (Figs 12 and 13). Many long oligodendrocyte chains were seen in the optic tract of Rat 2.

Changes in the nerve fibres were of an equally slight nature. A moderate degree of distortion appeared in the tract of Rat 2.

The nerves and tracts, however, revealed a high degree of patchy demyelinization, which was also present in the nerve head of Rat 7 . (Fig. 14). None was found in Rat 4. Several hard grey plaques were found (Fig. 15).

The sciatic nerves showed circumferential degeneration involving some of the nerve trunks (Fig. 16). In others, there was distortion of the myelin sheaths when viewed transversely. Some sheaths exhibited ballooning. 


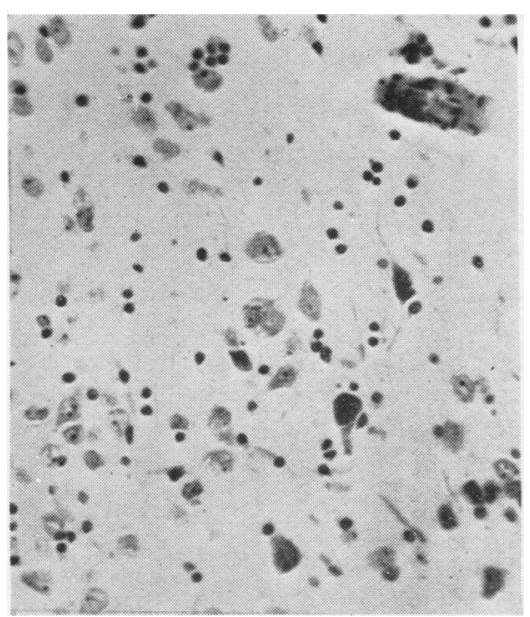

FIG. 12.-Hyperchromatic visual cellbodies, hyperchromatism of glia, and slight evidence of satellitosis in chronic thiamin deficiency 57 days after recovery. Giemsa $\times 220$.

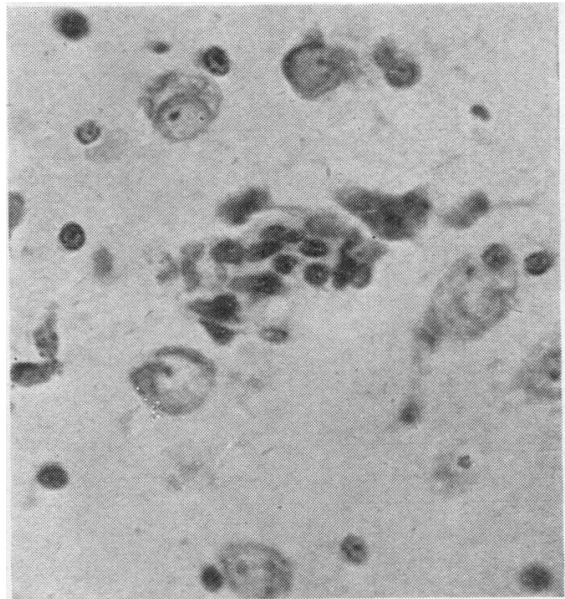

FIG. 13.-Satellitosis in recovered thiamin deficiency. Giemsa $\times 450$.

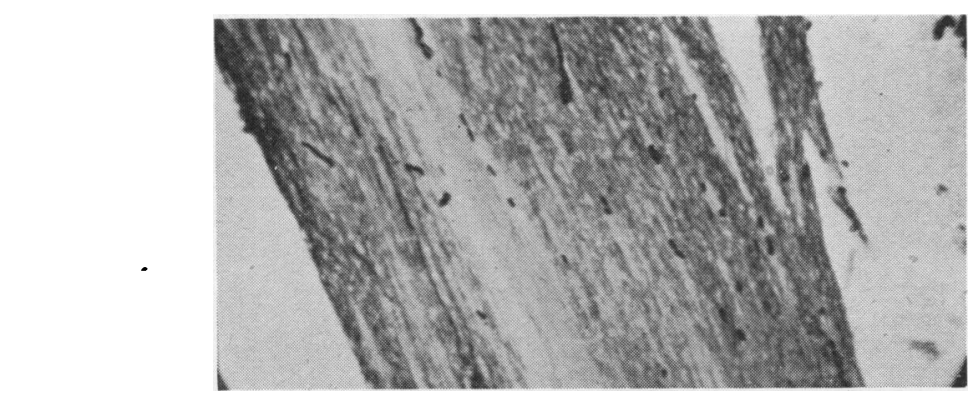

FIG. 14.-Central demyelinization of optic nerve in chronic thiamin deficiency. Loyez $\times 200$.

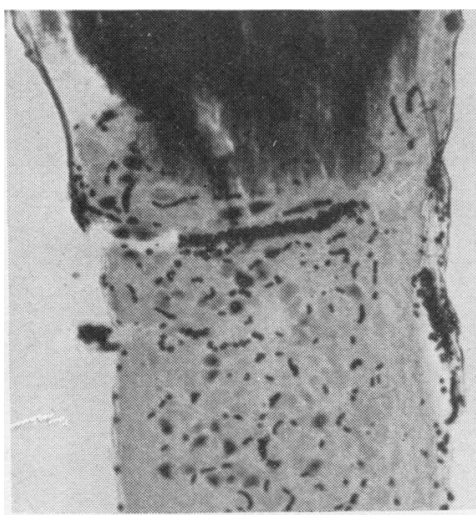

FIG. 15.-Hard grey plaque in optic tract in recovered chronic thiamin deficiency. Note clear delimitation of healthy sheaths above this region. Loyez $\times 150$

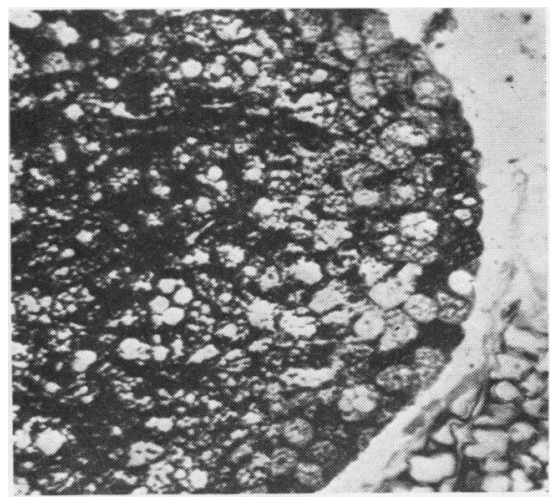

FIG. 16.-Persistent demyelinization of peripherally placed fibres in a large sciatic nerve twig in recovered chronic thiamin deficiency. Weigert-Pal $\times 140$. 


\section{(6A) Paired Control}

Diet.-As in Experiment 6.

Clinical Behaviour.-Weights and heart rates are shown in Table VII.

As anorexia in the experimental rats had been well controlled, these rats flourished, seldom appearing hungry.

TABLE VII

EXPERIMENT 6A, PAIRED CONTROLS (DURATION 140 DAYS)

\begin{tabular}{c|c|c|c|c|c}
\hline & \multicolumn{2}{|c|}{ Weights (g.) } & \multicolumn{2}{c|}{ Heart Rates (beats/min.) } & \multirow{2}{*}{ Disposal } \\
\cline { 2 - 5 } Rat No. & Initial & Final & Initial & Final & \\
\hline 2A & 110 & 220 & 480 & 440 & \\
4A & 55 & 190 & 500 & 480 & Killed on 140th day \\
7A & 60 & 188 & 500 & 480 &
\end{tabular}

Pathological Observations.-No abnormality found.

\section{Discussion}

The results of these experiments show that optic and sciatic nerve atrophy can be produced in rats fed a diet high in carbohydrate at a level of thiamin inadequate for health, but sufficient to keep the animals alive over a period of about 180 days.

The degeneration found in the visual pathways of rats fed under such circumstances consisted of a slight degree of hyperchromatism and sclerosis of the retinal ganglion cells, and in more marked degree of the cells in the dorsal nucleus of the lateral geniculate body. In addition there was a striking proliferation within the optic nerve and tract of oligodendrocytes which formed long interfascicular chains; rod cells were present in great abundance in the dorsal nucleus; and here and there in the same region neuroglial hyperchromatism. The most important sign of all was the tortuosity, varicosity, and fragmentation of the visual fibres, especially of their central terminations. Enlargement of synaptic boutons and an increase in argyrophil ring shapes were also seen. The myelin sheaths in their turn exhibited a patchy demyelinization, several soft plaques were observed, and, in many of the persistent sheaths, irregularity of outline and ballooning.

These changes, indicative of severe neuronal degeneration, were found to be reversible with the following exceptions. The proliferation of the glia persisted 76 days after re-institution of a full diet, as did the glial hyperchromatism; the nerve fibres remained more tortuous than in the paired animals; the myelin lesions were for the greater part unchanged. A new feature in the recovered animals was the appearance of several hard grey plaques.

The paired control rats in the chronic thiamin deficiency experiment, 
having a high intake of thiamin, never presented this picture. They were under close observation throughout; their behaviour remained perfectly normal, and their appetites were excellent, although at times they went hungry. Subsequently, as has been said, the visual pathways revealed no abnormality whatsoever. It seems certain, then, that the histological changes in the central and peripheral nervous systems described above arose as a result of thiamin deficiency, and for no other reason. At any rate, anorexia had never been gross or prolonged in the deficient animals. The cell bodies within the central nervous system were distorted in those rats which were made to die of inanition at the end of 18 days, but the peripheral processes were never affected. This, it is believed, is a highly significant observation, yet, in the paired controls, not even this change was found.

The changes found in the sciatic nerves in chronic thiamin deficiency were striking, but should be stressed again that they were not examined in every case, nor was every twig sectioned in those nerves chosen. It is certain, however, that here as in the optic nerve demyelinization of a gross nature resulted. The interesting feature is that the degenerative process appeared to affect some twigs and not others in the same nerve, and that it was the peripheral fibres in a twig which were affected first. This perhaps explains the discrepancies expressed in the literature. These myelin changes were for the greater part irreversible. For the same reasons as are given above, inanition could not be responsible.

In acute thiamin deficiency, inanition was gross in the last day or two of life, yet the visual pathway was not affected other than by a slight cloudy swelling of the retinal bipolars. There was no fragmentation nor demyelinization of the visual fibres, nor was there sclerosis of the geniculate neurones. The marked demyelinization found in the sciatic nerves may have been due to this terminal inanition, but the evidence does not altogether support this view. In the two 'inanition' experiments, the sciatic nerve changes were not marked. Under the polarizing microscope, there was some granular isotropism of the myelin, but no more than that. Nevertheless, since the rats used were older, one hesitates to be dogmatic in claiming that acute thiamin deficiency leads to sciatic nerve atrophy, though it certainly appears to accentuate it, in the presence of inanition.

It was interesting to find that in acute deficiency, the gross myelin changes found in the sciatic nerves were recoverable, whereas in chronic deficiency, the less gross changes were not recoverable. It is possible that the degree of myelin-recovery depends upon the integrity of the nerve cells and their processes, for in acute deficiency (by analogy with the state of the visual neurones) the latter were intact, whereas in the chronic condition there were always residual signs of cell-body disease. On these grounds it seems probable that as a general rule the integrity of myelin depends upon the integrity of the cell-body, although the reverse is obviously not true. This belief has been expressed by several workers in the past. 
To return to the visual neurones, just as different rats appear to be more susceptible, so some fibres seem to be more readily affected than others. As we do not know the pathway taken by the macular fibres in the rat, however, we could not say, even if only the central fibres had degenerated, that the papillo-macular bundle was more susceptible than any other.

It is important to note that the lesions produced in myelin by a thiamin deficiency of long duration were disseminated throughout the visual pathway, and increased in severity as they ascended. This fact lends support to our belief that the retinal ganglion cells are not greatly affected, a somewhat paradoxical finding in view of their extremely low resistance to chemical poisons, and the generally held opinion that the causative agent in thiamin deficiency is an endogenous toxin, specifically affecting the macula.

The appearance of the retina in the chronic experiments, however, suggests that, if the thiamin deficiency had been even more prolonged, the retinal ganglion cells would have become just as much affected in the end as were the visual cells of the diencephalon. Perhaps the explanation of the long retinal immunity is to be found in the extremely active drainage afforded by the choriocapillaris.

Changes affecting the retinal pigment or the blood vessels were not found in any specimen. Furthermore, there was a total lack within the visual path of any sign of a haemorrhagic crisis, although the Giemsa technique is particularly suited for such observations. Although the floor of the IVth ventricle was not investigated and this is the preferential site for such haemorrhages in the rat, we seem to have been justified in leaving the rat to manufacture its own vitamin $\mathrm{K}$.

The endogenous supply of vitamin $\mathrm{C}$ was also adequate for there were no signs of scurvy.

\section{Summary}

(1) When thiamin deficiency in rats is of moderate degree and prolonged for about 180 days or over, degeneration of the visual pathway develops in certain susceptible animals, its intensity being greatest centrally. This occurs even when the caloric intake is adequate.

(2) A chronic degeneration of this type comprises three distinctive features:

(a) The visual cells become sclerosed and hyperchromatic, the retinal much later than the geniculate.

(b) The axis cylinders become thickened, tortuous, and varicose, the terminal branches fragmented, and the nerve endings enlarged. Ring shapes increase.

(c) Multiple foci of demyelinization occur, to be replaced in time by clearly delimited glial plaques.

(d) Long chains of oligodendrocytes form, and rod cells appear in the lateral geniculate body. 
(3) The chronic deficiency is also associated with demyelinization of some of the twigs of the sciatic nerves, affecting particularly the peripheral fibres.

(4) These changes are reversible only when the cell-body and its process has not been unduly damaged. Myelin-sheath recovery is probably dependent upon complete recovery of the soma.

(5) In acute thiamin deficiency, the visual pathway is not affected, but the sciatic nerves become grossly demyelinated. This demyelinization is completely reversible. It is probably associated with inanition.

(6) Demyelinization of the sciatic nerves also occurs in rats fed a diet totally inadequate in calories with or without vitamins, but in this case is much less gross than when combined with acute thiamin deficiency.

My thanks are due to the Research Committee of the Medical School, King's College, Newcastle, for a grant which enabled me to prosecute this work.

\section{REFERENCES}

Arnold, A., and ElvehJem, C. A. (1938). J. Nutr., 15, 403.

Barletta, V. (1932). Rass. ital. Ottal., 1, 210.

Berry, C., NeumanN, C., and Hinsey, J. C. (1945). J. Neurophysiol., 8, 315.

Best, C. H., and TAYloR, N. B. (1950). "The Physiological Basis of Medical Practice", 5 th ed. Baillière, Tindall and Cox, London.

CowARD, K. H. (1947). "The Biological Standardisation of the Vitamins ", 2nd ed. Baillière, Tindall and Cox, London.

Davison, C., and Stone, L. (1937). Arch. Path., Chicago, 23, 207.

Drummond, J. C., and Marrian, G. F. (1926). Biochem. J., 20, 1229.

Drury, A. N., Harris, L. J., and Maudsley, C. (1930). Ibid., 24, 1632.

Engel, R. W., and Phillips, P. H. (1938). J. Nutr., 16, 585.

FERRARO, A., and RoIzIN, L. (1943). J. Neur.opath., 2, 392.

Follis, R. H., Miller, M. H., Wintrobe, M. M., and Stein, H. J. (1943). Amer. J. Path., $19,341$.

Leinfelder, P. J., and RobBie, W. A. (1947). Amer. J. Ophthal., 30, 1135.

McDermott, W., Webster, B., Baker, R., Lockhart, J., and Tompsett, R. (1943). J. Pharmacol., 77, 24.

Marchesini, E., and Papagno, M. (1935). Ann. Ottal., 63, 81.

Peters, R. A. (1934). Proc. roy. Soc. Med., 27, 478.

Prados, M., and Swank, R. L. (1942). Arch. Neurol. Psychiat., 47, 626.

Prickett, C. O. (1934). Amer. J. Physiol., 107, 459. Salmon, W. D., and Schrader, G. A. (1939). Amer. J. Path., 15, 251.

Rodger, F. C. (1951). "The Relationship of Thiamin to the Visual Pathway". Thesis. Glasgow University.

Shaw, J. H., and Phillips, P. H. (1945). J. Nutr., 29, 113.

SWANK, R. L., and BESSEY, O. A. (1941). Ibid., 22, 77.

and Prados, M. (1942). Arch. Neurol. Psychiat., Chicago, 47, 97.

Wintrobe, M. M., Follis, R. H., Humphreys, S., Stein, H., and Lauritsen, M. (1944). J. Nutr., 28, 283.

Woolley, D. W., and White, A. G. C. (1943). J. biol. Chem., 149, 285.

YUDKIN, J. (1951). Biochem. J., 48, 608.

Zimmerman, H. M. (1943). Res. Publ. Ass. nerv. ment. Dis., 22, 51 and 75. 